\title{
Effects of Ingested Multi-Walled Carbon Nanotubes in Poecilia reticulata: Localization and Physiological Responses
}

\section{Dumsile W Nyembe ${ }^{1,2 *}$, Victor Wepener ${ }^{2}$, Bhekie B Mamba ${ }^{1}$ and Ndeke Musee ${ }^{3}$}

${ }^{1}$ Department of Applied Chemistry, University of Johannesburg, PO Box 17011, Doornfontein, Johannesburg, 2028, South Africa

${ }^{2}$ Department of Zoology, University of Johannesburg, PO Box 534, Auckland Park 2006, South Africa

${ }^{3}$ Department of Chemical Engineering, University of Pretoria, Private Bag X20, Hatfield 0028, Pretoria, South Africa

\begin{abstract}
Multiwalled carbon nanotubes (MWCNTs) are among the nanomaterials earmarked for water purification, yet they have been reported to cause toxicity in fresh water species. This study was conducted to investigate the histopathological and physiological effects of MWCNTs in freshwater fish (Poecilia reticulata). Literature reports that physicochemical properties of MWCNTs could be linked to their toxicological effects, hence the MWCNTs used in this study were characterized prior to (for physical and chemical properties) and during testing (for chemical interactions). Fourier transmission infra-red spectroscopy (FT-IR) revealed additional functional groups in oxidized multiwalled carbon nanotubes (o-MWCNTs) that were absent in the pristine multiwalled carbon nanotubes ( $p$-MWCNTs). Transmission electron microscopy (TEM) and energy dispersive X-ray (EDX) also revealed amorphous carbon and residual Fe catalyst only in $p$-MWCNTs. The fish were exposed for $96 \mathrm{~h}$ in suspensions of $p$-MWCNTs and o-MWCNTs prepared by sonicating in moderately hard reconstituted water to test toxicity. Zeta potential measurements revealed an impartation of a negative charge onto MWCNT surfaces by HA, whilst hydrodynamic size measurements revealed aggregation/ disaggregation occurring alternately over the 96-h exposure time. Apart from only fish hyperactivity, no mortality was observed for $96-\mathrm{h}$ acute tests for up to $300 \mathrm{mg} / \mathrm{L}$ MWCNT concentration. Histopathology revealed that MWCNTs aggregates were deposited mainly in the gut where they caused inflammation, hemorrhaging and oedema which were characterized by fragmented fibrin. Cell lyses also occurred in o-MWCNT exposed fish as evidenced by nuclei clusters among o-MWCNT aggregates. Statistical analysis by 2-way ANOVA followed by Bonferroni posttests showed that significant $(p<0.05)$ reactive oxygen species $(R O S)$ was induced as indicated by depleted antioxidant capacity (TCA), superoxide dismutase (SOD), lipid peroxidase (MDA) and protein carbonyl (PC) content between 3.25 and 15.0 $\mathrm{mg} / \mathrm{L}$ of MWCNTs. These effects were attributed to the MWCNTs' physicochemical properties as predetermined by functionalization (acid oxidation). The obtained results indicate that indeed MWCNTs cause toxic effects in freshwater fish, and although depuration was evident, there is a risk of MWCNT trophic transfer to fish eaters.
\end{abstract}

Keywords: MWCNTs characterization; Freshwater; Fish; Histopathology; ROS

\section{Introduction}

In recent years, nanotechnology has attracted a lot of attention because of the increasing human ability to synthesize and manipulate nanomaterials. Due to the potential of this technology there has been a worldwide increase in investment in its research and development [1]. Among other needs, there is a rising demand for clean water, on our planet which has been brought about by prolonged droughts, population boom, strict health-based regulations and competitive demand from different users [2,3]. New advances in water treatment suggest that many of the issues involving water quality could be resolved or greatly improved by using nanoproducts [4,5]. Carbon nanotubes (CNTs) are among the nanomaterials that have attracted the greatest attention with regards to the water problem [6]. Among the well-known CNTs in this class are multiwalled carbon nanotubes (MWCNTs). Although to date the knowledge about their transport, environmental fate, and toxicity is on the rise than ever before, their toxicity and mechanisms are still not fully understood. On the hand, toxic effects of some CBNs have been reported in early toxicity studies even though most of the data in these reports are conflicting and the debate on testing methods is on-going, yet on the other hand, forecasted huge increase in manufacture and use of nanomaterials makes it likely that increased environmental exposure to them will occur.

Freshwater organisms, such as fish, are particularly at risks as they could be exposed to nanomaterials via municipal and industrial wastewaters and wearing out of nano-products [7]. Nanomaterial persistence, inertness and interaction with living organisms govern their toxic properties which in turn depend on their physicochemical properties [8,9]. Physicochemical properties such as concentration, size, surface characteristics, and aggregative propensities of nanomaterials are known to impact their aquatic toxicity because they influence the capability of aquatic organisms to absorb them (bioavailability) $[10,11]$. Fish are known to accumulate nanoparticles mainly in the gut $[12,13]$; it has been demonstrated that fish gills are sensitive to singlewalled carbon nanotubes (SWCNTs) [14] and that their adsorption and attachment onto the cell surface compromise cellular integrity and function. Multiwalled carbon nanotubes (MWCNTs) are another class of carbon-based nanomaterials (CBNs) just like SWCNTs, hence may also be bioavailable to fish and other aquatic vertebrates as they could be taken up via gills and mouth $[15,16]$. Due to these factors, the concept of intrinsic toxicity of manufactured nanomaterials needs to be linked with measurements in field or simulated field media.

In recent years, environmental risks associated with CBNs have been evaluated using aquatic toxicology $[17,18]$ which is a tool that

*Corresponding author: Dumsile W. Nyembe, Department of Applied Chemistry, University of Johannesburg, PO Box 17011, Doornfontein, Johannesburg 2028, South Africa, Tel: 0834283312; E-mail: nyembedumsile@yahoo.com

Received April 14, 2016; Accepted April 21, 2016; Published April 26, 2016

Citation: Nyembe DW, Wepener V, Mamba BB, Musee N (2016) Effects of Ingested Multi-Walled Carbon Nanotubes in Poecilia reticulata: Localization and Physiological Responses. J Environ Anal Toxicol 6: 368. doi:10.4172/21610525.1000368

Copyright: (c) 2016 Nyembe DW, et al. This is an open-access article distributed under the terms of the Creative Commons Attribution License, which permits unrestricted use, distribution, and reproduction in any medium, provided the original author and source are credited. 
measures acute lethality and sub-lethal toxicity [19]. There is therefore, the need to elucidate the link between physicochemical properties with observed toxicological effects of CBNs to freshwater species at acute and sub-lethal concentrations. Normally, acute toxicity reports the lethal concentrations at different population levels that is $50 \%$ $\left(\mathrm{LC}_{50}\right)$ or $20 \%\left(\mathrm{LC}_{20}\right)$ of the population, whereby mortality, growth or reproduction is the end point. Acute toxicity results usually help in designing sub-lethal toxicity tests which are aimed at determining the mechanisms of toxicity [20]. Some CBN mechanisms of toxicity point to cellular membrane damage through the generation of reactive oxygen species (ROS) which may lead to lipid peroxidation, damage of proteins, and nucleic acids [21]. In vivo toxicity response depends on the degree of alterations of the nanomaterial's structure, such as in functionalization of the nanomaterial [22] performed according to the purpose of application. These very properties that give nanomaterials such commercial promise, which include small size, very high surface area to mass ratio, and high chemical reactivity, may also result in greater toxicity than their bulky counterparts [23]. This is because the resultant nanomaterials can penetrate an organism's body via various routes and could persist in the system due to the incapacity of macrophages to phagocytize them [24], hence researchers are in the quest to determine the underlying mechanisms of toxicity.

Histology, originally used in evaluating the degree of pollution effects [25], is yet another tool that is becoming another way of assessing nanomaterial environmental risks. In vivo studies that map localization of CBNs and with those that have reported mechanisms of their toxicity and reconciled them with mechanisms of toxicity are still very few. Therefore, in order to contribute to the body of knowledge, the present study reports the effects of physicochemical properties of synthesized pristine ( $p-)$ and acid oxidized (o-) MWCNTs on 96-h acute and sub- lethal toxicity tests on juvenile fish (Poecilia reticulata). Haematoxylin \& Eosin (H\&E) staining and light microscopy helped identify MWCNT target organs following MWCNT ingestion. The MWCNTs were suspended in moderately hard reconstituted water with $5 \mathrm{mg} / \mathrm{L} \mathrm{HA}$ to mimic some natural freshwater environment at which MWCNT hydrodynamic size and surface charge were monitored over the 96-h acute toxicity exposure period. Besides the fact that fish are part of the standard protocol recommended by OECD as USEPA [20] they were chosen as a test organism in this study because their position in the trophic hierarchy signifies that their level of health can indicate the health of other organisms in the ecosystem.

\section{Materials and Methods}

\section{Synthesis and characterization}

The MWCNTs investigated in the present study were synthesized in our laboratories using the nebulised spray pyrolysis (NSP) method as described by Vivekchand et al. [26] and Salipira et al. [27]. Pristine MWCNTs ( $p$-MWCNTs) were the $\mathrm{HCl}$-washed as- prepared form which had been rinsed in several washes with deionised water until a neutral $\mathrm{pH}$ was achieved. A portion of these was oxidised by refluxing in $1: 3 \mathrm{H}_{2} \mathrm{SO}_{4}: \mathrm{HNO}_{3}$ for $24 \mathrm{~h}$ in order to generate $o$-MWCNTs. The $p$-MWCNTs and $o$-MWCNTs were characterized for their: bands that proved their successful synthesis (Raman spectroscopy, Perkin Elmer Raman nicroscope, RamanMicro 200), shape (A JEOL 100S and Tecnai G2 Spirit transmission electron microscope (TEM)), purity (Energy Dispersive X-ray (EDX) spectroscopy), successful functionalization of $p$-MWCNTs to $o$-MWCNTs (Fourier transmission infrared (FTIR), Perkin Elmer Spectrum 100 FTIR spectrometer) prior to the toxicity studies [28]. The characterization techniques gave an insight to the physical properties and chemical composition of the MWCNTs.

\section{Poecilia reticulata (fish) toxicity tests}

Fish handling upon delivery: The fish used were sourced from a local supplier at Kirsten Aquaculture in Modimolle, South Africa. Prior to fish fry delivery, reconstituted moderately hard water was prepared using $\mathrm{NaHCO}_{3}(96 \mathrm{mg} / \mathrm{L}), \mathrm{KCl}(4 \mathrm{mg} / \mathrm{L}), \mathrm{MgSO}_{4} 7 \mathrm{H}_{2} \mathrm{O}(60 \mathrm{mg} / \mathrm{L})$, and $\mathrm{CaSO}_{4} \cdot \mathrm{H}_{2} \mathrm{O}(60 \mathrm{mg} / \mathrm{L})$, with an overall alkalinity of $\geq 57$ - in accordance with the Guideline 202 of Organization for Economic Cooperation and Development (OECD) [29]. The prepared reconstituted moderately hard water was placed in two $8 \mathrm{~L}$ glass aquariums and aerated for $24 \mathrm{~h}$ prior to use so as to maintain dissolved oxygen at $>80 \%$. The aquariums were kept in an environmentally controlled room at a constant temperature of $22 \pm 1^{\circ} \mathrm{C}$ with $16 \mathrm{~h}$ light and $8 \mathrm{~h}$ dark periods. The fish were delivered in plastic-bagged media, hence upon delivery, in the bags they came in; they were placed in the prepared aquariums for $2 \mathrm{~h}$ of acclimatization. After the $2 \mathrm{~h}$ the fish were gently let out of the bags to swim freely in the aquariums. The aquariums were kept in an environmentally controlled room at a constant temperature of $22 \pm 1^{\circ} \mathrm{C}$ with $16 \mathrm{~h}$ light and $8 \mathrm{~h}$ dark periods until their ripe age of 14-17 days after which they were used in the static non- renewal 96-h acute and sub-lethal exposure tests. The fish were maintained by feeding them commercial fish food which was not given $48 \mathrm{~h}$ before the tests. The toxicity tests were carried out following OECD guidelines 203 [30] with in-house adjustments customised to cater for MWCNT aggregative propensity, dark colour of the, as well as the objectives of the study. Surplus and older fish were surrendered to in-house fish husbandry at the University of Johannesburg.

Fish 96-h acute lethality test: Poecilia reticulata (fish) exposed to 5 concentrations of serially diluted $p$-MWCNTs and $o$ - MWCNTs of between $15 \mathrm{mg} / \mathrm{L}, 30 \mathrm{mg} / \mathrm{L}, 75 \mathrm{mg} / \mathrm{L}, 150 \mathrm{mg} / \mathrm{L}, 300 \mathrm{mg} / \mathrm{L}$ prepared by sonicating in moderately hard reconstituted water prepared in Milli-Q water in the presence of $5 \mathrm{mg} / \mathrm{L}$ humic acid (HA) to mimic natural freshwater. Three negative controls (without MWCNTs) were included together with 3 positive controls of $100 \mathrm{mg} / \mathrm{L}$ potassium dichromate $\left(\mathrm{K}_{2} \mathrm{Cr}_{2} \mathrm{O}_{7}\right)$. The tests were set up in triplicates, with 5 neonates in each of the three $600 \mathrm{~mL}$ beakers with $400 \mathrm{~mL}$ MWCNT suspensions. Three 600 $\mathrm{mL}$ beakers were set for negative controls and contained only dilution water without MWCNTs. Dissolved oxygen (DO) was maintained at more than $80 \%$ and conductivity at $<10 \mu \mathrm{S} / \mathrm{cm}$ at the beginning of the test. The tests were run at $\mathrm{pH} 7.4$ and $22 \pm 1{ }^{\circ} \mathrm{C}$ temperature with light and dark cycles of $16: 8 \mathrm{~h}$ for the duration of the $96 \mathrm{~h}$. These toxicity tests resulted in no mortality for the set time for all the concentrations. However, any abnormal fish behaviour was noted and the $30 \mathrm{mg} / \mathrm{L}$ MWCNT tests were nominally chosen and saved for histology.

Fish tests for biomarker assays (sub-lethal tests): For these tests it was decided that the MWCNT concentrations are brought down to concentrations that would aggregate/settle-out less and also not cause the hyperactivity observed in the acute lethality tests. Similar to the acute lethality tests, in the sub-lethal tests MWCNTs were sonicated in moderately hard water to constitute $0.83 \mathrm{mg} / \mathrm{L}, 1.63 \mathrm{mg} / \mathrm{L}, 3.25 \mathrm{mg} / \mathrm{L}$, $7.5 \mathrm{mg} / \mathrm{L}$, and $15 \mathrm{mg} / \mathrm{L}$ in the presence of $5 \mathrm{mg} / \mathrm{L}$ humic acid (HA) to mimic some natural freshwaters. The tests were run in triplicates set up with 7 neonates (enough for biomarker work) for each treatment concentration, in $600 \mathrm{~mL}$ beakers with $400 \mathrm{~mL}$ MWCNT suspensions. Negative and positive controls, $\mathrm{pH}$, conductivity, DO, temperature, and light and dark cycles were set up as in acute lethality tests.

Hydrodynamic size and surface charge of $30 \mathrm{mg} / \mathrm{L}$ MWCNT suspensions: Aggregate size, usually measured as the hydrodynamic size, has been linked to aggravated toxicity of nanomaterials and nanoparticles; hence it was monitored throughout the 96-h period of 
the acute lethality test. Hydrodynamic size and surface charge were measured together with surface charge, measured as zeta potential $(\zeta$-potential), using a Malvern ZetaSizer, Nano series, NanoZS. Since histopathological examination was performed on fish suspended in 30 $\mathrm{mg} / \mathrm{L}$ MWCNT suspensions it is the results of the hydrodynamic sizes at this concentration that are reported herein.

Histopathology of whole juvenile fish exposed at $30 \mathrm{mg} / \mathrm{L}$ MWCNT suspensions: Histology was conducted to determine localization and physiological effects of $p$-MWCNTs and $o$-MWCNTs in the Poecilia reticulata. At the end of the 96-h exposure, fish exposed to the acute lethality concentration of $30 \mathrm{mg} / \mathrm{L}$ MWCNT suspensions were collected, anesthetized and sacrificed before fixing in Bouin's solution and over $24 \mathrm{~h}$ in $50 \mathrm{ml}$ screw-cap glass vials. The fixative used was predetermined as $50 \mathrm{ml}$ for every 5 fish fry to satisfy the 10:1 ratio pre- condition. Bouin's solution decalcifies bone adequately to minimize sectioning artefacts, and enhance staining [31]. Then, the fish samples were removed from the Bouin's solution and washed with tap water and dehydrated in different grades of alcohols. They were then cleared in xylene and embedded in paraffin wax and shaped into blocks. Thin sections of $5 \mu \mathrm{m}$ were cut out from the blocks, and placed on microscope slides before staining with haematoxylin $(\mathrm{H})$ and eosin $(\mathrm{E})$ [32]. The obtained sections were viewed under a Zeiss light microscope.

Fish biomarker assays: The sub-lethal MWCNT-exposed juvenile fish were collected and sacrificed for determination of Hydrogen peroxide $\left(\mathrm{H}_{2} \mathrm{O}_{2}\right)$ content $(\mathrm{mM})$, superoxide dismutase (SOD) content (U/mg protein) content using a Sigma Aldrich kit, Total Antioxidant Capacity (TAC) in $\mathrm{mM}$ using a Cell Biolabs' OxiSelect ${ }^{\mathrm{m}}$ kit, Malondaldehyde (MDA) content in $\mathrm{nmol} / \mathrm{mg}$ protein using a Sigma Aldrich kit, and Protein Carbonyl (PC) content (nmol/mg protein) also with a kit from Sigma Aldrich. Protein content was determined on the sample supernatants (in $\mathrm{mg} / \mathrm{L}$ ) according to Bradford [33] and the obtained protein results were used to quantify the biomarkers. Whole fish specimens of $0.1 \mathrm{~g}$ (7 neonates) were initially homogenized in icecold $0.1 \mathrm{M}$ phosphate buffered saline (PBS) at $\mathrm{pH} 7.4$ using a metallic homogenizer immersed in an ice bath to obtain a $10 \%$ homogenate which was then centrifuged at $3000 \mathrm{rpm}$ for $10 \mathrm{~min}$ at $4^{\circ} \mathrm{C}$. For future biomarker analysis, the resultant supernatants were collected and snap frozen at $-80^{\circ} \mathrm{C}$ in Eppendorf tubes labelled according to the MWCNT exposure suspensions from which the fish were taken were. For immediate biomarker determination, cold $\left(4^{\circ} \mathrm{C}\right) 100 \mu \mathrm{L}$ aliquots of the supernatants of the centrifuged samples were transferred into new Eppendorf tubes with corresponding labels and diluted with $1 \mathrm{~mL}$ Milli-Q water - these were the final aliquots used in the biomarker analysis which were determined using protocols that the kit suppliers provided.

Statistical analysis: GraphPad Prism, Version 5 was used to analyse the biomarker data. All results are presented as the mean values and standard errors of the mean in 3 replicates of each treatment. Data was subjected to two-way analysis of variance (ANOVA) followed by Bonferroni post-tests following the procedure in GraphPad Prism, Version 5. The confidence interval used was $p<0.05$. The Bonferroni posttests tested if: (i) MWCNT type (i.e., $p$-MWCNTs or $o$-MWCNTs) has the same effect at all values of MWCNT concentrations (interactions), (ii) MWCNT type (i.e., $p$-MWCNTs or $o$-MWCNTs) affects toxicity, and (iii) MWCNT concentration affects toxicity.

\section{Results}

\section{Characterization results}

MWCNT morphology and purity: The EDX and TEM show that there was residual Fe catalyst and amorphous carbon in the $p$ -
MWCNTs (Figure 1a and b), very little amorphous carbon and no residual $\mathrm{Fe}$ catalyst was found in $o$-MWCNTs as revealed by TEM (Figure 1c) and EDX (Figure 1d). Also, revealed by TEM was the high agglomerative behaviour in $p$-MWCNTs (Figure 1a) compared to $o$ - MWCNTs. Oxygen was also revealed by EDX (Figure 1d) on $o$-MWCNTs, which was as a result of the functionalization process.

MWCNT evidence of functionalization: The prominent Raman features in MWCNTs (Figure 2a) observed were D (disordered) and G (graphite) bands. The D-band was observed at near $1300 \mathrm{~cm}^{-1}$, whilst the G-band appeared around $1600 \mathrm{~cm}^{-1}$ [34]. Functionalization success was confirmed by functional groups revealed by FT-IR (Figure $2 \mathrm{~b}$ ). These were; $-\mathrm{C}=\mathrm{O}\left(1702 \mathrm{~cm}^{-1}\right),-\mathrm{OH}\left(1364 \mathrm{~cm}^{-1}\right)$ and $-\mathrm{C}-\mathrm{O}(1202 \mathrm{~cm}$ $\left.{ }^{1}\right)$, corresponding to $-\mathrm{OH},-\mathrm{C}=\mathrm{O}$ and $-\mathrm{C}-\mathrm{O}$ stretching vibrations of carboxylic groups $(-\mathrm{COOH})$.

Hydrodynamic size and surface charge of $30 \mathrm{mg} / \mathrm{L}$ MWCNT suspensions: Surface charge ( $\zeta$-potential) and average mean aggregate size changes of $p$-MWCNT and $o$ - MWCNT over the 96-h exposure period are presented in Figure 3. The results indicate an impartation of a negative charge by HA onto the MWCNT surface which is indicated by an increase in negative $\zeta$-potential. The $\zeta$-potential of $p$-MWCNTs without $\mathrm{HA}$ was $0.0 \mathrm{mV}$ with an average mean aggregates of size $>500$ $\mathrm{nm}$ (Figure 3a), whilst $o$-MWCNT recorded an average aggregate size of $<400 \mathrm{~nm}$ and a $\zeta$-potential of $-3.3 \mathrm{mV}$ (Figure $3 \mathrm{~b}$ ). The introduction of $5 \mathrm{mg} / \mathrm{L}$ HA imparted negative charge which led to reduced mean aggregate sizes for both $p$-MWCNTs and $o$-MWCNTs over the $96 \mathrm{~h}$ period even though aggregation/disaggregation still occurred.

Fish acute lethality tests: Due to the absence of mortality and pronounced aggregation of $p$-MWCNTs and settling-out of solution of $o$-MWCNTs the lethality concentration to $50 \%$ of the fish population $\left(\mathrm{LC}_{50}\right)$ could not be quantified of at the tested concentrations. Pronounced aggregation and settling- out as the MWCNT concentrations were increased posed a problem of reporting inaccurate concentrations for the observed effects. However, the fish were observed to spend more time at the bottom of the beakers at the beginning of the tests and became hyperactive and restless after the first $24 \mathrm{~h}$ while by the end of the 96-h exposure period those exposed at 300 $\mathrm{mg} / \mathrm{L}$ MWCNTs had begun to slow down. The MWCNT aggregates were also seen adhering onto the skin of the fish.

Histopathology of whole juvenile fish exposed at $30 \mathrm{mg} / \mathrm{L}$ MWCNT suspensions: The prepared slides revealed the areas of localization (Figures 4a and b). The peritoneum near the liver is magnified for clarity in Figure 4c. Also, the slides indicate the aggregative patterns of the $p$-MWCNTs inside the fish intestines are magnified in Figures $4 \mathrm{~d}$ and $4 \mathrm{e}$ where it can be seen that the $p$-MWCNT aggregates caused inflammation of the mucosa layer. Epithelial damage and haemorrhaging inside the intestines were observed and evidenced by the eosinophilic polymerised fibrin sheets and fragments - which appear red amongst the aggregates - adhering onto the tissues characteristic of inflammatory response. Haemorrhaging was likely due to mechanical abrasion and the $30 \mathrm{mg} / \mathrm{L} p$-MWCNTs. Also, depurated $p$-MWCNTs through the fish's cloacae (Figure $4 \mathrm{f}$ ) were observed to be bearing some fibrin. The dark marks surrounding the gonads are haematoxylin staining artefacts and not MWCNTs.

Aggregates of $o$-MWCNTs were also found in the fish's gut as presented in Figure 5a. Also worth noting were clusters of nuclei (stained blue) - a feature that was less pronounced in $p$ - MWCNT sections (Figure 5b). The nuclei clusters signify cell lyses. The pink dots circled in Figure 5b were staining artefacts and not MWCNT 
Citation: Nyembe DW, Wepener V, Mamba BB, Musee N (2016) Effects of Ingested Multi-Walled Carbon Nanotubes in Poecilia reticulata: Localization and Physiological Responses. J Environ Anal Toxicol 6: 368. doi:10.4172/2161-0525.1000368

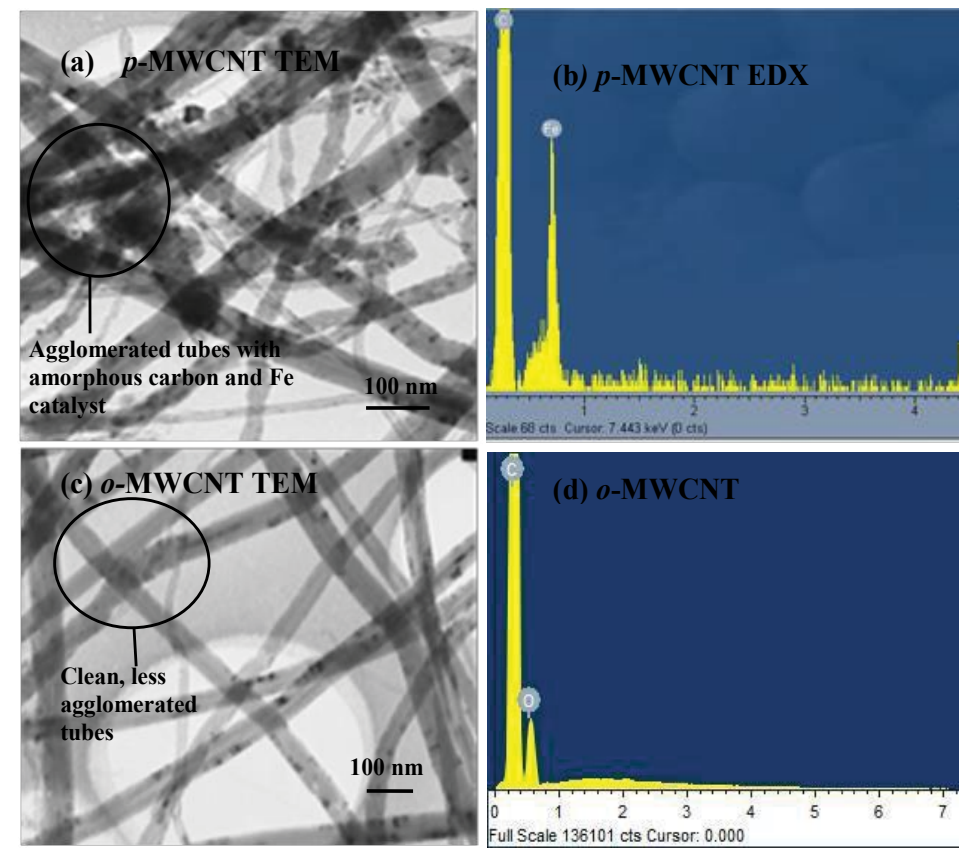

Figure 1: (a) TEM showing highly agglomerated $p$-MWCNTs with impurities (b) EDX for $p$-MWCNTs showing a Fe peak for residual catalyst in the impurities. (c) TEM showing less agglomerated o-MWCNT clean tubes and (d) EDX for o-MWCNTs with no trace of residual Fe catalyst.

(a) Raman spectroscopy of $p$-MWCNTs and $o$-MWCNTs

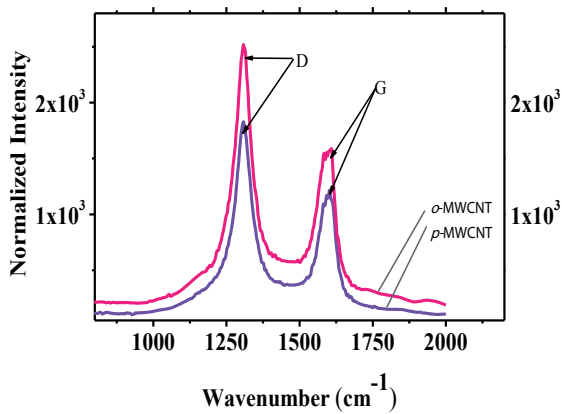

\section{(b) FT-IR of $p$-MWCNTs and $o$-MWCNTs}

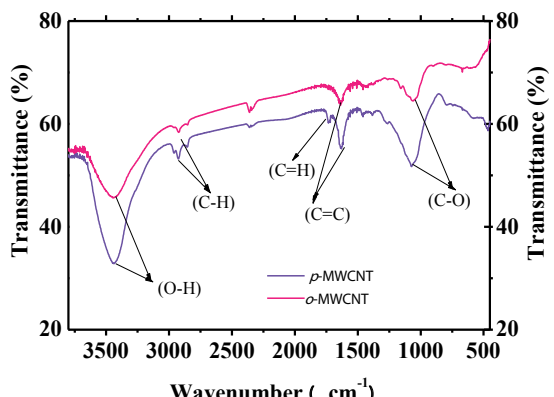

Wavenumber $\left(\mathrm{cm}^{-1}\right)$

Figure 2: (a) Raman spectroscopy showing the typical MWCNT D- and G- bands. (b) FT- IR for p-MWCNTs and o-MWCNTs shows the major peaks on the MWCNTs.

(a)

p-MWCNT mean aggregate size and surface charge over $96 \mathrm{~h}$

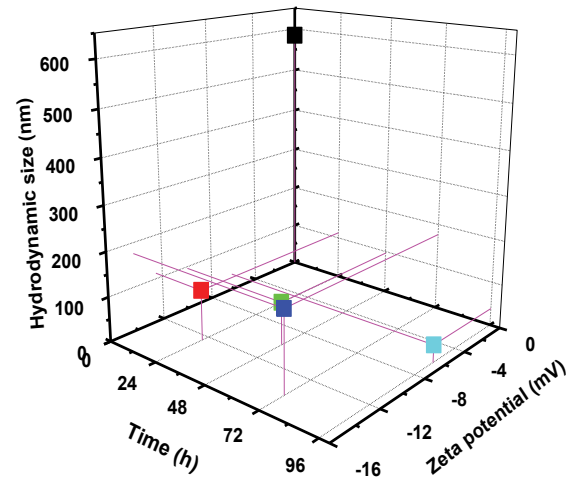

(b)

o-MWCNT mean aggregate size and surface charge over $96 \mathrm{~h}$

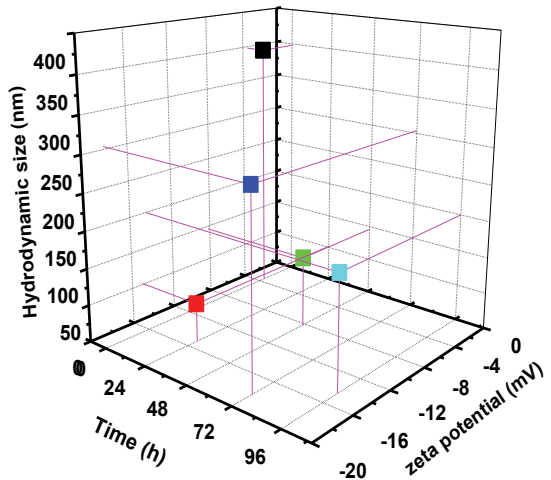

Figure 3: Coloured square marks represent surface charge and hydrodynamic size measurements of $30 \mathrm{mg} / \mathrm{L}$ (a) represent $p$-MWCNTs, and (b) o-MWCNTs, suspended in moderately hard water in the presence of $5 \mathrm{mg} / \mathrm{L} \mathrm{HA}$ over a $96 \mathrm{~h}$ period. In both (a) and (b) black square marks represent hydrodynamic size of the respective MWCNTs suspended without HA. 
effects. This indicates that in addition to inflammation, oedema, and haemorrhaging also occurred in fish exposed to $o$-MWCNTs. Just as $p$-MWCNTs, the $o$-MWCNTs also caused inflammation and oedema in the intestinal walls and clumps of nuclei were observed among $o$-MWCNT aggregates (Figure $5 \mathrm{c}$ and $5 \mathrm{~d}$ ) and polymerised fibrin appeared fragments among the aggregates.

Fish biomarker assays: Hydrogen peroxide $\left(\mathrm{H}_{2} \mathrm{O}_{2}\right)$ was evidently present in significant $(\mathrm{p}<0.05$ at $95 \% \mathrm{CI})$ amounts at MWCNT concentrations of $3.75-15.0 \mathrm{mg} / \mathrm{L}$ (Figure 6a). However, there was no statistically significant difference in the amounts of $\mathrm{H}_{2} \mathrm{O}_{2}$ produced by either $p$-MWCNTs or $o$-MWCNTs at each exposure concentration.

The sametrend wasobserved with SOD (Figure 6b). Totalantioxidant capacity revealed that the defence system was under significant stress at MWCNT concentrations of 3.75 to $15.0 \mathrm{mg} / \mathrm{L}$ (Figure 6c). Evidence of degradation of lipids was observed whereby $p$-MWCNTs and $o$ MWCNTs did not show statistically significant differences in the MDA content (Figure 6d). Furthermore, biomacromolecular degradation was observed with protein carbonylation (PC) in Figure 6e. Statistically significant PC content was observed in the presence of 3.75 to 15.0 $\mathrm{mg} / \mathrm{L}$ MWCNT concentrations.

\section{Discussion}

Since MWCNT type ( $p$-MWCNTs and $o$-MWCNTs) were obtained through functionalization (acid oxidation), this property dictates the differences in physicochemical properties of the MWCNTs: the uptake of nanoparticles is determined by their bioavailability which is influenced by their physicochemical properties and exposure medium chemical matrix. Since nanoparticles have been reported to exhibit different hydrodynamic sizes under the influence of the chemical matrix of the suspending medium [35], for the present study we therefore hypothesize that the aggregation/disaggregation process resulted from the ionic species in the moderately hard reconstituted water used, largely driven by the presence of HA and physicochemical properties of the MWCNTs (Figure 3). What was observed in the present study was a sharp decrease in mean aggregate sizes for both $p$-MWCNTs and $o$-MWCNTs in the presence of HA. Also, $\zeta$-potential measurements revealed evidence of negative charge impartation by HA onto the MWCNTs which resulted in repulsive forces that kept the particles apart - a phenomenon that favoured their bioavailability [36]. Even in the presence of HA the aggregation/disaggregation process still occurred throughout the exposure period, though the aggregates formed were much smaller than those in the absence of HA. Literature reports cite stability of nanoparticles in the presence of humic substances (Figure 3). Stable nanoparticles are known to be more bioavailable, but even ones that settle out of the suspending media are bio-available, especially to pelagic organisms that also exhibit a benthic lifestyle such as fish; fish were seen spending more time at the bottom of the beakers at the beginning of the tests, which exposed them more too settled-out $o$-MWCNTs.

It has been reported in literature that fish imbibes suspended water through stress-induced drinking [37] which may result in increased pollutant uptake. When fish are exposed to nanomaterials in water, the gut and skin become the main target organs [38]. It is hypothesised that such an occurrence happened with the fish exposed to the MWCNTs, which explains the observed hyperactivity of the fish in the acute toxicity tests. The hyperactivity can be associated to the skin and intestinal irritations resulting from direct contact with the MWCNTs (Figures 4 and 5). Hyperactive behaviour in older fish has been previously reported as a behavioural change presumably resulting from mechanistic damage to nerves or brain and neurotoxicity [14]. In the present study, events that are likely to have led to the observed behavioural changes in the exposed fish were evident; Inflammation caused by $p$-MWCNT and $o$-MWCNT aggregates along the fish's gut presented in Figures 4 and 5 resulted in the haemorrhaging of intestinal walls as outlined by Mumford et al. [39]. Also, nuclei, stained blue by haematoxylin in Figure 5d and 3 haemorrhaging, as evidenced by the presence of fibrin fragments, in $o$-MWCNT-exposed fish gut due to the abundance of $-\mathrm{COOH}$ groups introduced by acid oxidation in $o$-MWCNTs as revealed by FT-IR in Figure $2 \mathrm{~b}$, coupled with the mechanical abrasion caused by churning of the intestinal walls when peristaltic movements occurred during digestion [40]. In $p$-MWCNTexposed fish, haemorrhaging resulted from high aggregative propensity, hydrophobicity (signified by its pronounced agglomerative behaviour) as well as the amorphous carbon revealed by TEM (Figure 1a). Therefore, the observed gut damage by the MWCNTs was due to their adhesive and abrasive nature, surface charges, functional groups and hydrophobicity which made them highly affinitive for the mucous membranes of the intestinal walls [41,42]. Degeneration of the mucosa and necrosis are known to lead to permeability and absorption of substances mediated through them [43,44]. Mammalian gastrointestinal degradation by nanomaterials has been reported in literature [45]. Velmurugan et al. reported oedema, necrosis and atrophy of epithelial cells in fish intestines by monocrotophos, an organic pesticide [46], which is likely to have occurred in the present study, hence the clumps of nuclei among $o$-MWCNT aggregates in Figure 5d.

The specific affinity of the fibrin to the MWCNT aggregates observed in Figures 4 and 5 could be explained by chemical signals that result in rapid vasodilation and increased vascular permeability and protein rich fluid exudates that bathe injured and inflamed areas following injury [39]. The secreted fluid contains, among other components, eosinophilic fibrin, which in its polymerized form histologically appears as sheets or strands [39] as seen in Figures 4 and 5. In a study similar to the present, Smith and colleagues demonstrated CNT's affinity for mucous membranes in gill surfaces of fish [14]. In another study by Fraser et al. SWCNTs on juvenile rainbow trout, Onchorhychus mykiss, revealed a dose-dependent accumulation of the SWCNTs aggregated with gill mucous which increased mucous secretion, oedema, altered mucocytes and hyperplasia [47]. In a more recent study similar to the present, Bisesi et al. histologically showed that SWCNTs sloughed off gastrointestinal epithelial wall of the fish Pimephales promelas [48]. Such effects on intestinal walls could result to permanent ulceration and compromised nutrient absorption which may eventually kill the fish. Moreover, ulceration of the gut walls could make membranes susceptible to penetration of other xenobiotics which may be present in the water $[49,50]$. In the worst case scenario cancer could be caused, especially if cell defence mechanisms which scavenge free radicals become greatly compromised.

A balance between free radical production/scavenging and repair of damaged tissues exists in organisms that are not overwhelmed by oxidative stress [51]. The measured biomarker assays in the present study indicated that the MWCNT effects were dose-dependent [52]. Levels of $\mathrm{H}_{2} \mathrm{O}_{2}$ (Figure 6a) were elevated with increase in concentration. Total antioxidant capacity (Figure 6c) trend was observed to decrease with increase in MWCNT concentration, signifying a defence mechanism competent in curbing oxidative stress at lower MWCNT concentrations $(<3.25 \mathrm{mg} / \mathrm{L})$, but compromised as concentration increased $(\geq 3.5 \mathrm{mg} / \mathrm{L})$. This was also confirmed by a dose-dependent increased SOD (Figure 6b) alongside $\mathrm{H}_{2} \mathrm{O}_{2}$. A decrease in SOD is an 
Citation: Nyembe DW, Wepener V, Mamba BB, Musee N (2016) Effects of Ingested Multi-Walled Carbon Nanotubes in Poecilia reticulata: Localization and Physiological Responses. J Environ Anal Toxicol 6: 368. doi:10.4172/2161-0525.1000368
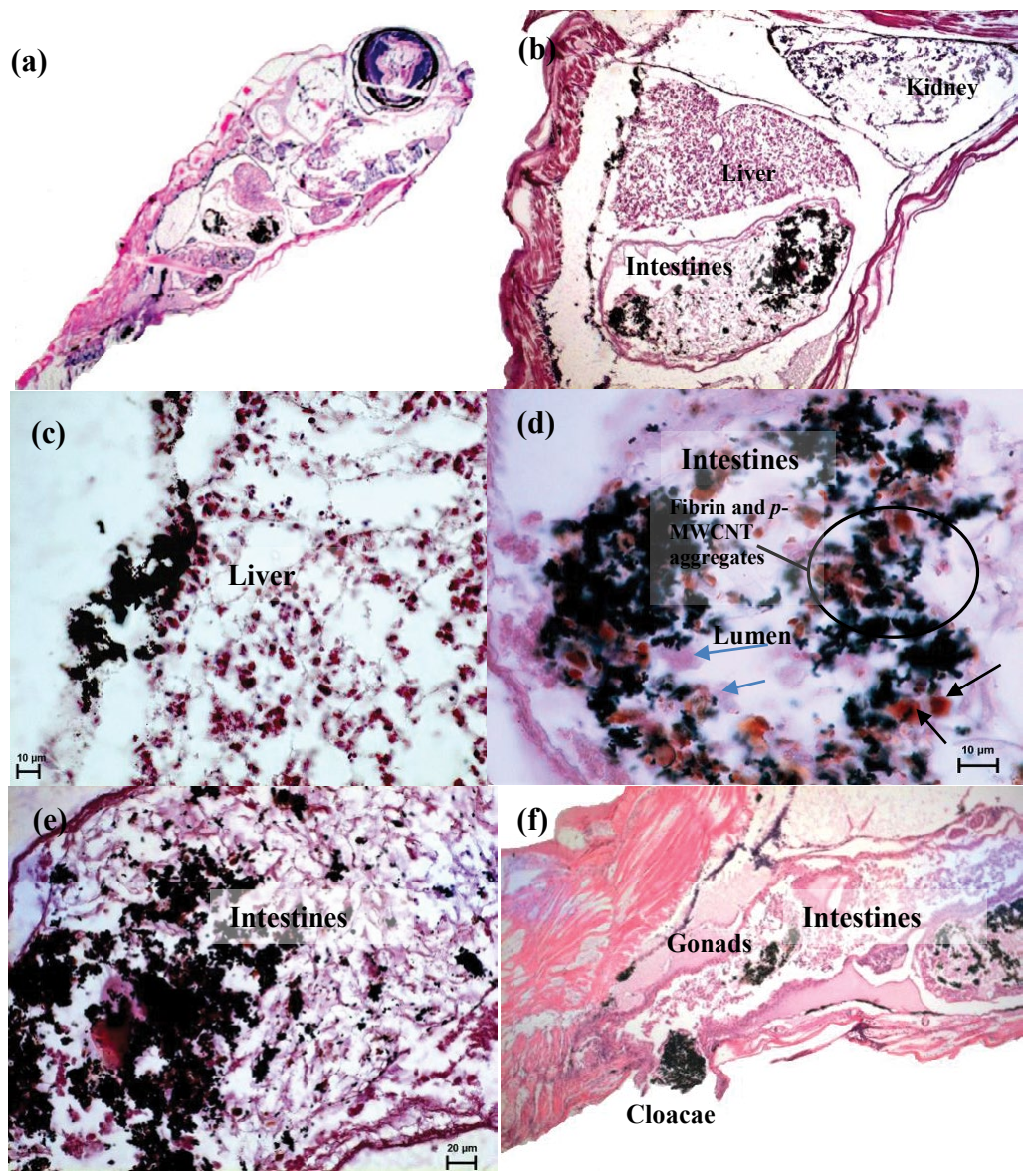

Figure 4: H\&E stained slides; (a) p-MWCNTs in P. reticulata, (b) magnified organs, (c) peritoneum near the liver with $p$-MWCNT deposits which must have been transferred during sectioning. (d) \& (e) Eosinophilic polymerized fibrin (red) among p-MWCNTs in gut. Blue arrows in (d) show evidence of a sloughed off epithelial wall, whilst black arrows show red stained fibrin sheets. (f) Depuration of fibrin-bearing $p$-MWCNT aggregates through the cloacae.

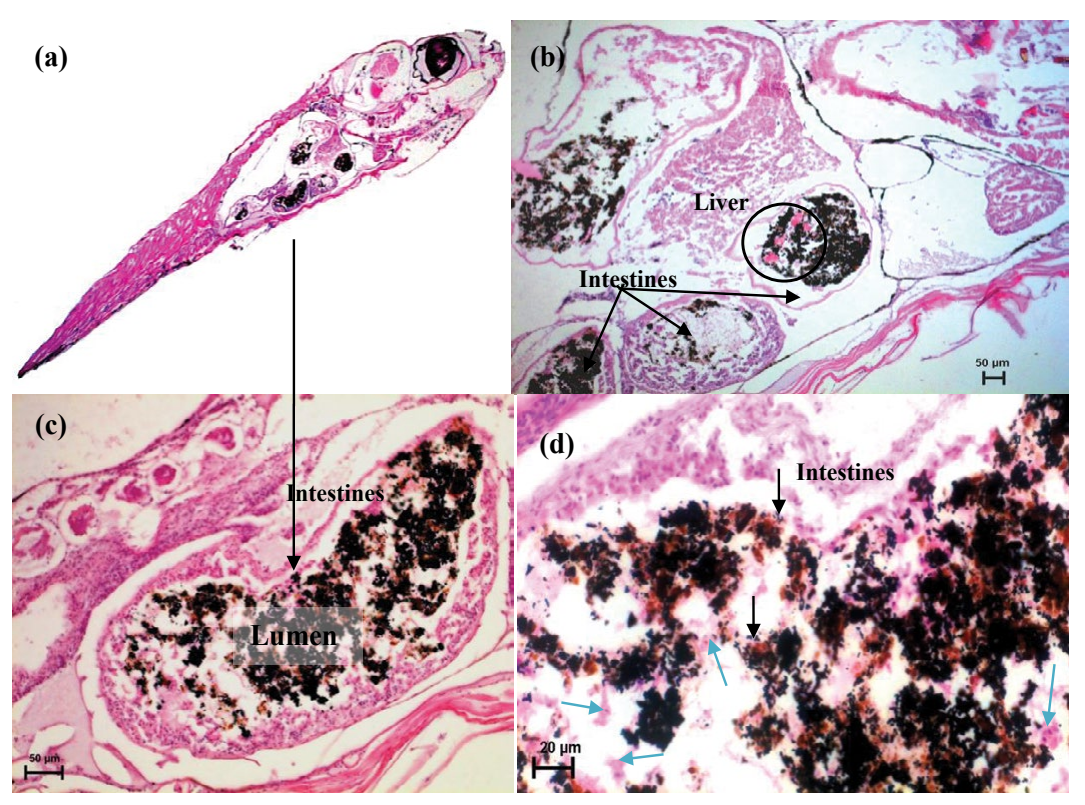

Figure 5: H\&E stained slides (a) and (b) mapping areas of o-MWCNT aggregate in $P$. reticulata. (c) o-MWCNTs aggregates in the fish's gut and the evidence of inflammation and haemorrhaging caused on the intestinal walls signified by the red coloured fibrin among the o-MWCNT aggregates. (d) Clusters of nuclei seen stained blue shown with black arrows among the aggregates, whilst blue arrows point at sloughed off epithelial wall. 
(a) $\mathrm{H}_{2} \mathrm{O}_{2}$ content

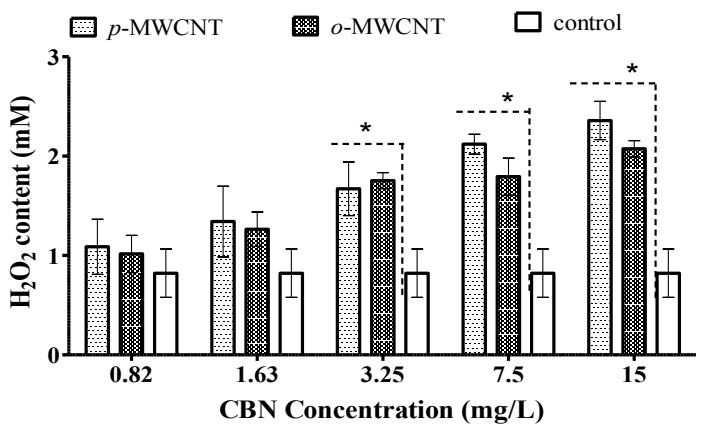

(b) Superoxide dismutase

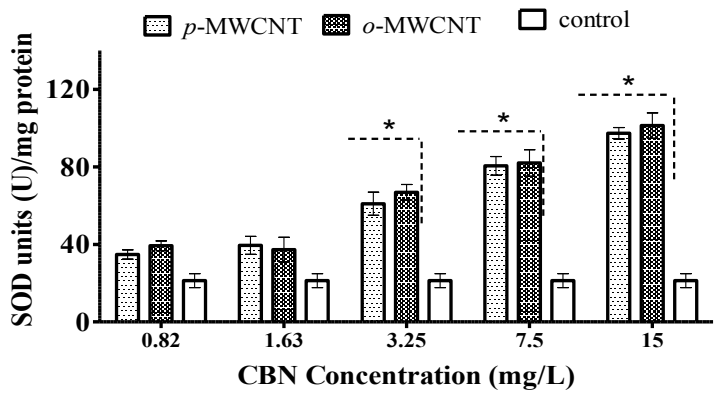

(d) Malondaldehyde content

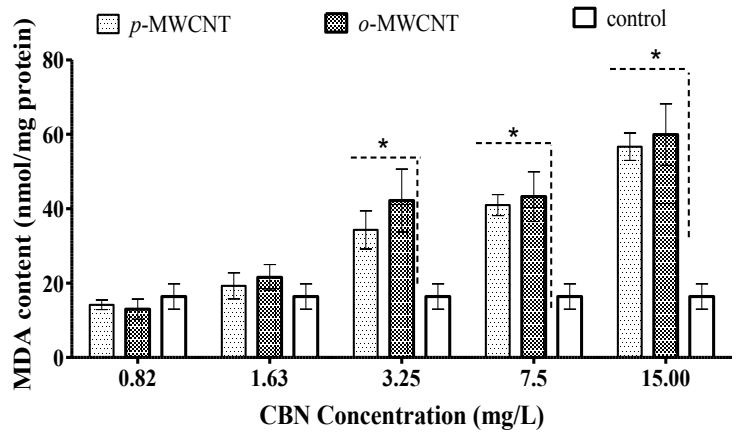

(c) Total antioxidant capacity
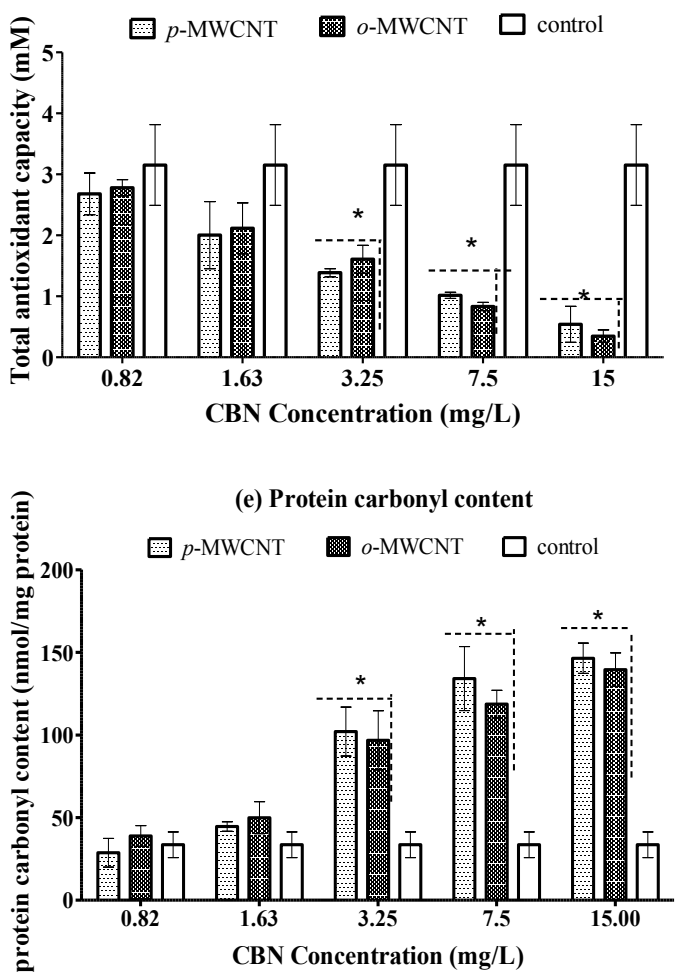

Figure 6: Results of (a) $\mathrm{H}_{2} \mathrm{O}_{2}$ content, (b) SOD (c) TAC, (d) MDA content and (e) PC content in the $P$. reticulata exposed for $96 \mathrm{~h}$ to $p$-MWCNTs and o-MWCNTs. The asterisk $\left(^{*}\right)$ indicates MWCNT exposure concentrations that resulted to statistically significant difference $(p<0.05)$ MDA content from the control. The error bars indicate standard error of the mean.

indication of loss in compensatory mechanisms that curb the effects of reactive oxygen species (ROS) [53,54]. Smith et al. in their study also observed induced ROS in the form of elevated $\mathrm{Na}^{+} / \mathrm{K}^{+}$ATPase in gills and intestines due to SWCNT localization [14]. While an increase of antioxidants is an indication of a competent system in warding off effects of xenobiotics, a depletion on the other hand is a sign of an overwhelmed system that may compromise biomacromolecules, such as lipids and proteins, and consequently affect cellular integrity $[55,56]$. Significant $(\mathrm{p}<0.05)$ lipid peroxidation was observed at 3.25 $\mathrm{mg} / \mathrm{L}$ of MWCNTs. Lipid peroxidation (Figure $6 \mathrm{~d}$ ) and protein oxidation (Figure 6e) also exhibited dose-dependent characteristics linked to the elevated $\mathrm{H}_{2} \mathrm{O}_{2}$ at MWCNT concentrations $\geq 3.25 \mathrm{mg} / \mathrm{L}$. $\mathrm{Zhu}$ et al. also reported pericardial oedema to embryos exposed to fullerenes and fullerol [57] which were alleviated by addition of GSH, thus suggesting free radical generated toxicity. It is also important to note that in their study Zhu et al. the dispersants were benzene, THF, and acetone. A considerable number of pioneering toxicity studies in reported literature, though they shed light on the toxic effects of CBNs, have used some form of dispersant in order to prepare stable CBNs for the purposes of in vivo studies, thus making it difficult to acquire clear information and draw commonalities.

\section{Conclusions}

Although aggregation of MWCNTs alternately occurred with disaggregation, the hydrodynamic sizes fell well within ingestible particle sizes. The presence of HA resulted in negative MWCNT surface charges. Histology and light microscopy revealed that the ingested $p$-MWCNTs and $o$-MWCNTs were deposited in the gut of 
Citation: Nyembe DW, Wepener V, Mamba BB, Musee N (2016) Effects of Ingested Multi-Walled Carbon Nanotubes in Poecilia reticulata: Localization and Physiological Responses. J Environ Anal Toxicol 6: 368. doi:10.4172/2161-0525.1000368

the Poecilia reticulata and were not found in any other major organs. The results revealed a particularly increased affinity of $p$ - MWCNTs' for biological membranes (gut wall) compared to $o$-MWCNTs. Moreover, $p$ - MWCNTs formed larger aggregates inside the fish gut than did $p$-MWCNT suspensions. This showed that hydrophobicity, a pronounced physicochemical property in $p$-MWCNTs, in the fish gut was not counteracted by the presence HA. Functionalization caused marked differences in the acute lethality tests since in addition to the inflammation and sloughing-off of the epithelial wall caused by both MWCNTs, $o$-MWCNTs further caused haemorrhaging of the intestinal walls which was evidenced by the presence of multiple nuclei among its aggregates. However, statistics revealed no significant differences in toxicities between the two MWCNTs at the measured sub-lethal concentrations. These irritations are likely to have been the cause of the observed abnormal behavioral changes in the fish in the acute lethality tests. It is therefore, concluded that MWCNTs are a gut irritant in juvenile fish which cause oxidative stress that adversely affects enzymatic activity, lipid peroxidation and carbonylation of proteins. The observed toxicity effects in this study raise concerns with regards to fish feeding organisms such as humans and birds. Therefore, protective majors have to be applied by industries manufacturing carbon nanomaterial products for use in the aquatic environment as they display a potential for excessive damage to the gut.

\section{Acknowledgements}

The authors are grateful to the National Research Foundation (NRF Innovation) (DWN), Centre for Nanomaterial Science Research (DWN), Nanotechnology Innovation Centre (DWN and BBM), University of Johannesburg (DWN, BBM, and VW), Department of Science and Technology (DST) (NM) and Centre of Scientific and Industrial Research (NM) for funding.

\section{References}

1. Guzman KAD, Taylor MR, Banfield JF (2006) Environmental risks of nanotechnology: national nanotechnology initiative funding, 2000-2004. Environ Sci Technol 40: 1401-1407.

2. MB Mohamed (2015) Low Cost Nanomaterials for Water Desalination and Purification. Final Technical report. Contract No. 4500103693. United Nations Educational, Scientific and Cultural Organization, pp: 1-38.

3. Savage N, Diallo MS (2005) Nanomaterials and water purification: Opportunities and challenges. J Nanopart Res 7: 331-342.

4. Colvin VL (2003) The potential environmental impact of engineered nanomaterials. Nat Biotechnol 21: 1166-1170.

5. John HG (1988) Using Desalination Technologies for Water Treatment. US Congress, Office of Technology Assessment, pp: 1-67.

6. Aqel A, El-Nour KMM, Ammar RAA, Al-Warthan A (2012) Carbon nanotubes science and technology part (I) structure, synthesis and characterisation. Arabian Journal of Chemistry 5: 1-23.

7. Buffle J (2006) The key role of environmental colloids/nanoparticles for the sustainability of life. Environ Chem 3: 155-158.

8. Nowack B, Bucheli TD (2007) Occurrence, behavior and effects of nanoparticles in the environment. Environ Pollut 150: 5-22.

9. Diallo MS, Glinka CJ, Goddard WA, Johnson JH (2007) Characterization of nanoparticles and colloids in aquatic systems. Small angle neutron scattering investigations of Suwanee River fulvic acid aggregates in aqueous solutions. J Nanoparticle Res 7: 435-448.

10. Bantz C, Koshkina O, Lang T, Galla H, Kirkpatrick HJ, et al. (2014) The surface properties of nanoparticles determine the agglomeration state and size of the particles under physiological conditions. Beilsein J Nanotechnol 5: 1774-1786.

11. Zhao F, Zhao Y, Liu Y, Chang X, Chen C, et al. (2011) Cellular uptake, intracellular trafficking, and cytotoxicity of nanomaterials. Small 7: 1322-1337.

12. Fernandes TF, Christofi N, Stone V (2007) The environmental implications of nanomaterials. In: Monteiro RN, Lang TC (eds.) Nanotoxicology: Characterization, Dosing and Health Effects. CRC Press, Boca Raton, USA, pp: 405-418.
13. Roberts AP, Mount AS, Seda B, Souther J, Qiao R, et al. (2007) In vivo biomodification of lipid-coated carbon nanotubes by Daphnia magna. Environ Sci Technol 41: 3025-3029.

14. Smith CJ, Shaw BJ, Handy RD (2007) Toxicity of single walled carbon nanotubes to rainbow trout (Oncorhynchus mykiss): respiratory toxicity, organ pathologies, and other physiological effects. Aquat Toxicol 82: 94-109.

15. Baun A, Sorensen SN, Rasmussen RF, Hartmann NB, Koch CB (2008) Toxicity and bioaccumulation of xenobiotic organic compounds in the presence of aqueous suspensions of aggregates of nano-C(60). Aquat Toxicol 86: 379-387.

16. Handy RD, Henry TB, Scown TM, Johnston BD, Tyler CR (2008) Manufactured nanoparticles: their uptake and effects on fish-a mechanistic analysis. Ecotoxicology 17: 396-409.

17. Handy RD, Cornelis G, Fernandes T (2012) Ecotoxicity test methods for engineered nanomaterials: practical experiences and recommendations fromthe bench. Environmental Toxicology and Chemistry 31: 15-31.

18. Kühnel D, Nickel C (2014) The OECD expert meeting on ecotoxicology and environmental fate--towards the development of improved OECD guidelines for the testing of nanomaterials. Sci Total Environ 472: 347-353.

19. Wepener V, Chapman PM (2012) South African ecotoxicology: present status and future prognosis. African Journal of Aquatic Science 37: 229-234.

20. Crane M, Handy RD, Garrod J, Owen R (2008) Ecotoxicity test methods and environmental hazard assessment for engineered nanoparticles. Ecotoxicology 17: 421-437.

21. Blickley TM, McClellan GP (2008) Toxicity of aqueous fullerene in adult and larval Fundulus heteroclitus. Environ Toxicol Chem 27: 1964-1971.

22. Stone V, Nowack B, Baun A, Brink VN, Kammer VF, et al. (2007) Nanomaterials for environmental studies: Classification, reference material issues and strategies for physico-chemical characterization. Sci Total Environ 408: 17451754.

23. Chapman PM (2002) Integrating toxicology and ecology: putting the "eco" into ecotoxicology. Mar Pollut Bull 44: 7-15.

24. Hirano S, Kanno S, Furuyama A (2008) Multi-walled carbon nanotubes injure the plasma membrane of macrophages. Toxicol Appl Pharmacol 232: 244-251.

25. Bernet D, Schmidt H, Meier W, Burkhardt HP, Wahli T (1999) Histopathology in fish: Proposal for protocol to assess aquatic pollution. J Fish Dis 12: $25-34$.

26. Vivekchand SRC, Cele LM, Deepack FL, Raju AR, Govindaraj A (2004) Carbon nanotubes by nebulised spray pyrolysis. Chemical Physics Letters 386: 313 318.

27. Salipira KL, Mamba BB, Krause RW, Malefetse TJ, Durbach SH (2008) Cyclodextrin Polyurethanes polymerised with carbon nanotubes for the removal of organic pollutants in water. Wat SA 34: 113-118.

28. Lukhele LP, Mamba BB, Musee N, Wepener V (2015) Acute toxicity of doublewalled carbon nanotubes to three aquatic organisms. Journal of Nanomaterials, pp: 1-19.

29. OECD (2000) Draft guidance document on aquatic toxicity testing of difficult substances and mixtures. Environmental Health and Safety Publications France, pp: 1-53.

30. OECD (1992) 203: fish, acute toxicity test. OECD Guidelines for Testing of Chemicals, France, pp: 1-10.

31. Bancroft JD, Gamble M (2008) Theory and practice of histology techniques. 6th Edn, Churchill Livingtone, Elsevier Health Sciences, p: 725

32. Roberts RJ (2002) Fish pathology. 3rd Edn. Journal of Fish Diseases, p: 125.

33. Bradford MM (1976) A rapid and sensitive method for the quantitation of microgram quantities of protein utilizing the principle of protein-dye binding Anal Biochem 72: 248-254

34. Dresselhaus M, Dresselhaus G, Saito R, Jorio A (2005) Raman spectra of grapheme ribbons. Physics Reports 409: 47-99.

35. Jiang J, Obedoster G, Biswas P (2009) Characterization of size, surface charge, and agglomeration state of nanoparticle dispersions for toxicological studies. Journal of nanoparticle Research 11: 77-89.

36. Schwyzer I, Kaegi R, Sigg L, Nowack B (2013) Colloidal stability of suspended and agglomerate structures of settled carbon nanotubes in different aqueous matrices. Water Res 47: 3910-3920. 
Citation: Nyembe DW, Wepener V, Mamba BB, Musee N (2016) Effects of Ingested Multi-Walled Carbon Nanotubes in Poecilia reticulata: Localization and Physiological Responses. J Environ Anal Toxicol 6: 368. doi:10.4172/2161-0525.1000368

37. Rorvik KA, Skjervold PO, Fjaera SO, Steiene SH (2002) Distended, water filled stomach in seawater farmed rainbow (Oncorhynchus mykiss) trout (Walbaum) provoked experimentally by osmoregulatory stress. Journal of Fish Diseases 3: 15-18.

38. Maes HM, Stibany F, Giefers S, Daniels B, Deutschmann B, et al. (2014) Accumulation and distribution of multiwalled carbon nanotubes in zebrafish (Danio rerio). Environ Sci Technol 48: 12256-12264.

39. Mumford S, Heidel J, Smith C, Morrison J, MacConnell B, et al. (2007) Fish Histology and Histopathology. USFWS-NCTC, pp: 1-357

40. Soenen SJ, Montenegro JM, Abdelmonem AM, Manshian BB, Doak SH, et al. (2014) The effect of nanoparticle degradation on amphiphilic polymer-coated quantum dot toxicity: the importance of particle functionality assessment in toxicology. Acta Biomater 10: 732-741.

41. Nazarenus M, Zhang Q, Soliman MG, Pino DP, Pelaz B, et al. (2014) In vitro interaction of colloidal nanoparticles with mammalian cells: What have we learned thus far? Beilstein J Nanotechnol 5: 1477-1490.

42. Seung WS, In HS, Soong HU (2015) Role of Physicochemical Properties in Nanoparticle Toxicity. Nanomaterials 5: 1351-1365.

43. Roberts RJ (2012) The Pathophysiology and Systematic Pathology of Teleosts. In: Fish Pathology, 4th Edn, Baillierre Tindall, London, UK.

44. Jumawan JC (2015) Histopathological effects of sub-acute lead chloride on the vital organs of the suckermouth sailfin catfish Pterygoplichthys pardalis Castelnau. International Journal of Fisheries and Aquatic Studies 2: 28-32.

45. Bellmann S, Carlander D, Fasano A, Momcilovic D, Scimeca JA, et al. (2015) Mammalian gastrointestinal tract parameters modulating the integrity, surface properties, and absorption of food-relevant nanomaterials. Wires nanomed Nanobiotechnol 7: 609-622.

46. Velmurugan B, Selvanayagam M, Cengiz El, Unlu E (2007) The effects of monocrotophos to different tissues of freshwater fish Cirrhinus mrigala. Bull Environ Contam Toxicol 78: 450-454.
47. Fraser TW, Reinardy HC, Shaw BJ, Henry TB, Handy RD (2011) Dietary toxicity of single-walled carbon nanotubes and fullerenes $(\mathrm{C} 60)$ in rainbow trout (Oncorhynchus mykiss). Nanotoxicology 5: 98-108.

48. Bisesi JH, Thuy N, Ponnavolu S (2015) Examination of Single-Walled Carbon nanotubes Uptake and Toxicity from Dietary Exposure: Tracking Movement and Impacts in the Gastrointestinal System. Nanomaterials 5: 1066-1086.

49. Garcia JC, Martinez DST, Alves OL, Barbieri E (2015) Ecotoxicology of carbofuran and oxidized multiwalled carbon nanotubes on the freshwate fish Nile tilapia: Nanotubes enhance pesticide ecotoxicity. Ecotoxicology and Environmental Safety 111: 131-137.

50. Martinez DST, Alves OL, Barbieri E (2013) Carbon nanotubes enhanced the lead toxicity on the freshwater fish. Journal of Physics 429: 1-9.

51. Calibrone AL (1985) Hand book of methods for oxygen radical research. CRC press, Boca Raton, USA, p: 447.

52. Manshian BB, Munck S, Agostinis P, Himmelreich U, Soenen J (2015) High content analysis at single cell level identifies different cellular responses dependent on nanomaterial concentrations. Sci Rep 5: 1-9.

53. Li ZH, Zlabek V, Velisek J (2011) Acute toxicity of carbamazepine to juvenile rainbow trout (Oncorhynchus mykiss): effects on antioxidant responses, hematological parameters and hepatic EROD. Ecotox Environ Safe 74: 319-327.

54. Jifa W, Yu Z, Xiuxian S, You W (2006) Response of integrated biomarkers of fish (Lateolabrax japonicus) exposed to benzo[a]pyrene and sodium dodecylbenzene sulfonate. Ecotoxicol Environ Saf 65: 230-236.

55. Prieto Al, Jos A, Pichardo S, Moreno I, Cameán AM (2006) Differential oxidative stress responses to microcystins $L R$ and $R R$ in intraperitoneally exposed tilapia fish (Oreochromis sp.). Aquat Toxicol 77: 314-321.

56. Halliwel B, Gutteridge JMC (1995) Free radicals in biology and medicine Oxford University Press, New York.

57. Zhu X, Zhu L, Li Y, Duan Z, Chen W, et al. (2007) Developmental toxicity in zebrafish (Danio rerio) embryos after exposure to manufactured nanomaterials: buckminsterfullerene aggregates (nC60) and fullerol. Environ Toxicol Chem 26 976-979. 